\title{
DIAGNÓSTICO DAS TURFAS NO BRASIL: HISTÓRICO DA UTILIZAÇÃO, CLASSIFICAÇÃO, GEOLOGIAE DADOS ECONÔMICOS
}

\author{
JOSÉ GUILHERME FRANCHI', JOEL BARBUJIANI SÍGOLO² \& JOSÉ FRANCISCO \\ MARCIANO MOTTA ${ }^{3}$
}

\begin{abstract}
Resumo Este trabalho fornece um panorama acerca do minério de turfa no Brasil. No aspecto geral, é abordada a classificação geológica e ecológica das turfeiras, com base em levantamento dos principais termos e conceitos coletados na literatura internacional relacionada a esses depósitos. Para o caso brasileiro, em particular, é apresentado um breve histórico dos fatores que condicionaram e restringiram a utilização da turfa, e analisa a distribuição regional e o condicionamento geológico dos principais depósitos. Do ponto de vista técnico-econômico, o estudo relaciona o quadro de reservas, a produção atual e as tendências do mercado.
\end{abstract}

Palavras chave: turfa, turfeira, classificação de turfeiras, reservas e produção de turfa

\begin{abstract}
PEAT REVIEW IN BRAZIL: HISTORICAL UTILIZATION, CLASSIFICATION, GEOLOGY AND ECONOMIC DATA This paper aims to review peat in Brazil. It gives a geological and ecological classification of peatlands, based on terms and concepts gathered from international literature related to these deposits. For the Brazilian specific situation, we present a brief overview concerning the main factors that have both stipulated and restrained its utilization at distinct periods in time, as well as the geology of the main deposits and their settling. From a technical-economical standpoint, this paper matches Brazilian reserves schedule with data related to both present production and market trends informed by some peat companies.
\end{abstract}

Keywords: peat, peatland, peatlands classification, Brazilian peat reserves and production

INTRODUÇÃO A turfa é utilizada há centenas de anos, principalmente em países do Hemisfério Norte, como um insumo energético (atendendo indústrias e pequenas centrais termelétricas) ou agrícola (substratos à formação de mudas e melhorador de solos). Em países de clima tropical, sua utilização é bem mais recente.

No caso particular do Brasil, o uso da turfa deve ser entendido à luz das alterações ocorridas na matriz energética ao longo da primeira metade do século XX, época em que o petróleo e o carvão mineral importados dominavam o cenário energético. $\mathrm{O}$ advento da $2^{\mathrm{a}}$ Grande Guerra parcialmente interrompe o fornecimento destes combustíveis, o que propiciou à Estrada de Ferro Central do Brasil, sem as formalidades exigidas pelo Código de Minas, autorização para alimentar suas locomotivas com o minério proveniente de turfeiras situadas no Vale do Paraíba, região que unia as duas principais cidades do país - São Paulo e Rio de Janeiro - e já acusava grande desenvolvimento industrial; algumas fábricas destas duas cidades já a utilizavam, também, como substituto da lenha. Constituem estes os primeiros registros do uso sistemático, embora efêmero, da turfa no Brasil. Entretanto, terminada a guerra e restabelecido o fornecimento do carvão e petróleo, a turfa foi abandonada como alternativa energética.

A partir de então, o petróleo adquire maior participação na matriz energética brasileira, devido às suas características energéticas favoráveis e às grandes descobertas havidas nas regiões do Cáucaso, Oriente Médio e Estados Unidos. No entanto, nos anos 70 , a constituição do cartel dos países exportadores, com a conseqüente elevação de preços, impôs enormes desequilíbrios nas balanças comerciais dos países importadores. Esforços consideráveis foram empreendidos, a partir de então, na execução de programas de pesquisa e desenvolvimento de fontes alternativas de energia com vistas à substituição, ao menos parcial, do petróleo importado.
Volta o carvão mineral a ocupar, então, posição de destaque na matriz energética do mundo industrializado. No Brasil, entretanto, mantiveram-se inalteradas as condições difficeis e onerosas de produção, transporte e distribuição deste bem mineral, além do elevado custo ambiental destas atividades; esta situação é agravada pela qualidade inferior dos nossos carvões, bem como pela localização geográfica, com as principais reservas concentradas na região Sul, de modo que barreiras econômicas inviabilizam sua utilização a norte do paralelo $20^{\circ} \mathrm{S}$.

Ainda no contexto da crise energética dos anos 70 , o interesse pela turfa foi intensificado em todo o mundo em vista à sua ampla disponibilidade e baixo custo de produção. No Brasil, destaca-se o trabalho desenvolvido pelo Departamento Nacional da Produção Mineral - DNPM - através da Companhia de Pesquisas de Recursos Minerais - CPRM -, o atual Serviço Geológico Nacional, que culminou com a descoberta de inúmeras turfeiras, fruto de vários projetos de prospeç̧ão regional mormente nas faixas litorâneas: Região Sul, Sudeste, Centro Oeste, Região do Alto São Francisco, Faixa Costeira da Bahia e Sergipe, Nordeste Oriental (AL, PE, PB, RN) e Nordeste Setentrional (MA, PI, CE). Foram dispendidos, também, alguns esforços no âmbito estadual, destacando estudos no Estado de São Paulo através da CESP - Companhia Energética de São Paulo e IPT - Instituto de Pesquisas Tecnológicas.

Duas das ocorrências caracterizadas à época alcançaram o estágio produtivo na década seguinte: a turfeira de Eugênio de Melo, situada na Bacia de Taubaté, município de São José dos Campos (SP), operada pela CESP prevendo a geração de energia termelétrica numa futura usina a ser construída, e a turfeira de Balneário Arroio do Silva, município de Araranguá (SC), que fornecia combustível aos fornos cerâmicos da CECRISA - Cerâmica Criciúma S/A.

A posterior normalização e estabilização dos preços mun-

1 - Instituto de Geociências - USP. Programa de Pós graduação em Geoquímica e Geotectônica. Rua do Lago, 562, Cidade Universitária, CEP 05508 080, São Paulo (SP), Brasil. E-mail: jfranchi@usp.br

2 - Instituto de Geociências - USP. Departamento de Geologia Sedimentar e Ambiental. Rua do Lago, 562, Cidade Universitária, CEP 05508-080, São Paulo (SP), Brasil. E-mail: jbsigolo@usp.br

3 - Instituto de Pesquisas Tecnológicas do Estado de São Paulo S.A.- IPT. Av. Prof. Almeida Prado, 532, Cidade Universitária, CEP 05508-901, São Paulo (SP), Brasil. E-mail: jfmotta(a)ipt.br 
diais do petróleo trouxeram uma série de fatores impeditivos à continuidade de utilização da turfa para este fim no Brasil, destacando-se, principalmente, a pouca competitividade econômica perante os derivados do petróleo e outras fontes alternativas (lenha, carvão vegetal, casca de coco, bagaço de cana, pneus velhos, etc.); no caso específico da turfeira paulista, acresceramse problemas de cunho ambiental além de reservas pequenas em vista do elevado consumo requerido para a geração de energia.

Este quadro conduziu a um redirecionamento das atividades daquelas minas, que passaram a produzir voltadas notadamente ao mercado agrícola, bem como à finalização dos grandes programas prospectivos conduzidos pelo sistema DNPM/CPRM.

A crise de abastecimento de petróleo dos anos 70 também representou, mundo afora, um marco decisivo para diversas outras aplicações das turfas, além da energética. Pesquisadores de diversos países, notadamente China, Canadá, Estados Unidos e Reino Unido dedicaram-se, nestas últimas três décadas, a estudos objetivando seu aproveitamento no tratamento de águas residuárias, sejam elas industriais ou domésticas, tema de inquestionável relevância em tempos atuais. No Brasil, alguns estudos acadêmicos foram conduzidos objetivando aplicações agronômicas das turfas como melhorador de solos para recuperação de áreas degradadas (Zimmermann 2001, Franchi et al. 2003), bem como na descontaminação de efluentes líquidos, como agente adsorvente de metais pesados (Santos 1998, Petroni et al. 2000, Petroni 2004).

CLASSIFICAÇ̃̃O DAS TURFEIRAS Turfeiras brasileiras foram classificadas por Abreu (1973) em duas categorias: as constituídas por gramíneas, ciperáceas e outras plantas de pântano, e as constituídas por algas ou sapropelitos, de aspecto lamoso e praticamente desprovidas de restos de plantas superiores.

Foram propostas diversas classificações para as turfeiras, em sua grande maioria para os depósitos existentes nos países de clima temperado do Hemisfério Norte, baseadas em critérios diversos: botânicos (turfeiras de florestas ou lenhosas, herbáceas e mistas), geográficos (parálicas e límnicas), no grau de decomposição das turfas geradas (turfeiras não-humificadas ou de musgos, e turfeiras humificadas ou combustíveis), etc. A diversidade das classificações existentes deve-se, predominantemente ao centro de interesse dos autores envolvidos e, de modo subsidiário, à sua formação acadêmica, uma vez que se encontram entre os principais estudiosos das turfas profissionais dos mais variados campos do conhecimento: engenharia, geociências, agronomia, biologia, medicina, arqueologia, ciências ambientais, florestais, etc.

Embora os trabalhos consultados revelem um tratamento perfunctório entre as classificações propostas, suas abordagens não são excludentes, haja vista a importância dos parâmetros considerados prioritariamente em cada uma. Embora se reconheça a dificuldade em se promover uma integração destes dados, acredita-se que eles podem ser agrupados segundo dois critérios principais: um geológico e outro ecológico.

Em termos geológicos, as turfeiras são consideradas análogos modernos dos depósitos de carvão paleozóicos e mesozóicos, passíveis de fornecer subsídios valiosos à interpretação paleogeográfica, ambiental, sedimentológica e mineralógica destes antigos depósitos carbonosos. Desta forma, podem ser classificadas como depósitos associados aos ambientes deltaico, estuarino e fluvial.

Por outro lado, parâmetros intrínsecos do ambiente formador como clima, topografia, hidrologia e quimismo das águas refletem-se na sucessão florística e constituição botânica da turfeira originada; segundo este critério, aqui designado ecológico, seriam as turfeiras classificadas em ombrotróficas e minerotróficas.

Critério Ecológico Os ecossistemas aquáticos (wetlands) podem apresentar as seguintes denominações: mire, bog, fen, mar- sh, moor, muskeg, swamp, e peatland. Os termos "pântano, brejo, lamaçal, charco", palavras sinônimas em língua portuguesa, são as traduções existentes nos dicionários para tais termos da língua inglesa; entretanto, nos países de origem, eles apresentam sensíveis diferenças e, mesmo, empregos diferentes, principalmente quanto à vegetação, morfologia e aspectos hidrológicos do ambiente.

O termo mire, segundo Gore (1983) é internacionalmente aceito para designar os sistemas formadores de turfa.

Fatores hidrológicos são os responsáveis pelos dois principais ambientes formadores de turfeiras (Moore 1989, Shotyk 1988):

- ambientes minerotróficos ou reotróficos (grego rhéos = riacho, fluxo; água corrente; grego trophé = nutrição, alimento), característicos de fens e swamps; originam turfeiras cuja vegetação esteve sob influência de águas provenientes dos limites externos à bacia de acumulação, e/ou subterrâneas;

- ambientes ombrotróficos (grego ómbros = chuva), característicos de bogs, que originam turfeiras cuja vegetação foi alimentada exclusivamente por águas de precipitação (chuva e/ou neve).

Segundo Gore (1983), o termo minerotrófico significa suprimento de água à vegetação proveniente da drenagem das terras mais altas adjacentes, enriquecidas em íons solubilizados das rochas; tal suprimento pode ser eutrófico (grego eu = bom; bem) ou oligotrófico (grego olígos = pouco), termos que, embora utilizados mais freqüentemente em limnologia para descrever produtividade planctônica, têm, aqui, um significado eminentemente químico.

O termo "trofismo" (trophy) indica a condição na qual a disponibilidade de nutrientes limita o desenvolvimento das plantas em qualquer turfeira (Clymo 1983).

Para Moore (1989), o viés hidrológico não é considerado na maioria das publicações técnicas sobre o assunto, onde raramente observa-se alguma distinção entre o caráter reotrófico ou ombrotrófico destes ecossistemas.

TURFEIRAS OMBROTRÓFICAS Shotyk (1988) define bogs como turfeiras ombrotróficas e freqüentemente convexas (daí os termos turfeiras elevadas ou domeadas). São particularmente comuns em áreas de elevada umidade atmosférica e baixa evapotranspiração como, por exemplo, nas regiões costeiras do Canadá, Escócia e Irlanda. Em função da convexidade do depósito, a matéria orgânica que se acumula não recebe a influência das águas de escoamento superficial e subterrâneas.

Uma vez que as águas superficiais destas turfeiras não recebem influxos significativos de cátions, as substâncias produzidas pela decomposição da matéria orgânica, responsáveis pela acidez do meio ( $\mathrm{CO}_{2}$ e ácidos orgânicos), não são neutralizadas, fato que confere a estas águas $\mathrm{pH}$ próximo ao valor 4; reside aí o principal motivo da elevada acidez deste tipo de turfeira. Com nutrientes minerais em baixas concentrações, aliado ao baixo $\mathrm{pH}$ das águas, tais turfeiras desenvolvem-se em ambiente oligotrófico. $\mathrm{O}$ oxigênio dissolvido em suas águas é consumido mais rapidamente que fornecido; daí a anaerobiose do ambiente.

Como resultado, turfeiras ombrotróficas apresentam diversidade de espécies vegetais relativamente pobre.

Em regiões de clima temperado são dominadas por briófitas do gênero Sphagnum, cujas exigências são relativamente baixas quanto ao suprimento de nutrientes ao meio. Árvores usualmente estão ausentes em bogs e, quando presentes, apresentam-se raquíticas e freqüentemente retorcidas.

Raised swamps é a denominação utilizada por McCabe (1984) para este tipo de turfeira, passível de desenvolvimento apenas em locais onde as taxas precipitação pluviométrica suplantem as de evaporação. Estas turfeiras apresentam comuni- 
dades florísticas com forte zoneamento concêntrico em função da acidez crescente das águas nas porções mais centrais; estas condições levam ao decréscimo do número de espécies e a formas mais raquíticas e anãs em direção ao centro do depósito.

Em função da maior uniformidade da vegetação e por não estarem sujeitas às freqüentes inundações nem às enxurradas das terras altas vizinhas, o minério resultante é extremamente pobre em cinzas (normalmente menos que $1 \%$ referente à base seca), segundo Clymo (1983).

As elevadas taxas de acresção observadas neste ambiente podem resultar antes da baixa taxa de decomposição que da alta produtividade vegetal. De fato, Moore (1989) ressalta que o estado de preservação da matéria vegetal em bogs é freqüentemente muito bom e mesmo os mais delicados tecidos das folhas das briófitas podem ser encontrados praticamente intactos. Dentre os fatores que mais contribuem a estas baixas taxas de decomposição, incluem-se a saturação permanente por água (algumas espécies destes musgos podem reter até 20 vezes seu próprio peso em água), o baixo $\mathrm{pH}$ (produzido, em parte, pelas propriedades de troca iônica do Sphagnum que liberam íons de hidrogênio para o meio), além da produção de toxinas antibióticas por estas plantas.

Lenz (1984) num trabalho de síntese acerca dos projetos de prospecção regional de turfa no litoral do nordeste brasileiro (geologia, reservas, métodos de lavra e economicidade como insumo energético regional) denomina esta classe de turfeiras como turfeiras altas, de pântanos altos ou ombrógenas; ressalta que elas não foram encontradas no litoral do nordeste brasileiro.

\section{TURFEIRAS MINEROTRÓFICAS OU REOTRÓFICAS}

Em contraposição ao regime hidráulico próprio e autônomo das ombrotróficas, as turfeiras minerotróficas (Shotyk 1988, Gore 1983, Clymo 1983) ou reotróficas (Moore 1989) são as que recebem o influxo de águas superficiais e subterrâneas enriquecidas em nutrientes minerais.

Para Shotyk (1988), nesta classe de turfeiras os ácidos resultantes da decomposição orgânica são neutralizados pelas bases provenientes da dissolução mineral e suas águas possuem um pH relativamente alto ( 6 a 8 ).

São classificadas, no Hemisfério Norte, em fens e swamps.

Fens, para Shotyk (1988), apresentam-se morfologicamente como extensas superfícies aplainadas, predominantemente constituídas por vegetação de gramíneas ("sedges") do gênero Carex, embora algumas variedades de Sphagnum, mormente as mais exigentes (Sphagnum teres e $S$. warnstorfii), também sejam comuns.

Swamps são fens com árvores na literatura americana. Segundo Shotyk (1988), o termo swamp é utilizado para descrever imensos tratos de solos bastante ricos, contendo árvores e outros tipos de vegetais em profusão mas encharcados em demasia para qualquer tipo de cultivo.

Em contrapartida, na literatura européia, swamps representam turfeiras dominadas por herbáceas monocotiledôneas altas, segundo Moore (1989). Este autor reafirma o entendimento de Shotyk relativamente ao conceito existente na América do Norte sobre o termo adicionando que, nestes países, as swamps de conceito europeu são denominadas "marsh".

Swamps fiorestadas na Europa recebem a denominação sueca Carr (MOORE, 1989), e apresentam lençol freático no verão freqüentemente abaixo da superfície de acúmulo vegetal, fato que leva à exposição ao ar e a baixas taxas de preservação da matéria orgânica como turfa.

Lenz (1984), embora sem utilizar as denominações "reotróficas" ou "minerotróficas", associa a esta categoria as turfeiras do nordeste brasileiro, denominando-as de turfeiras baixas, de pântanos baixos ou, ainda, topógenas, sendo desenvolvidas em formas negativas do terreno e restritas a ambientes flúvio-lacustres e lagunares.

Critério geológico Os autores que reportam o ambiente sedimentar como fator mais importante no desenvolvimento das turfeiras denominam genericamente swamps os ambientes formadores de turfa, sem fazer qualquer menção ou distinção destes com fens e/ou bogs.

A julgar pelos depósitos de carvão descritos em associação com sedimentos glaciais, fluviais, leques aluviais, eólicos e mesmo vulcanoclásticos (McCabe 1984), a turfa pode ocorrer nos mais variados ambientes sedimentares terrestres.

Para a geração de um depósito de carvão, a turfeira tem que ser "afogada" e/ou rapidamente soterrada por sedimentos clásticos. Compilação feita por Ryer \& Langer (1980), junto a vários trabalhos, aponta valores para taxas de compactação turfa: carvão entre $1,4: 1$ a $30: 1$, substancialmente maiores que para qualquer outro tipo de sedimento; sendo 7:1 a taxa média obtida desta compilação, grandes espessuras de turfa seriam esperadas para justificar-se boa parte dos depósitos de carvão conhecidos. Espessuras desta ordem são possíveis apenas em turfeiras em subsidência, seja por movimentos eustáticos ou tectônicos.

\section{TURFEIRAS ASSOCIADAS A AMBIENTE DELTAI-}

CO McCabe (1984) afirma que a maioria dos depósitos comerciais de carvão tem sido interpretada, ao menos em alguma etapa de seu desenvolvimento, como sendo deltaica, não sendo raro geólogos argumentarem pertencer a este ambiente toda seqüência sedimentar que apresente camadas de carvão. Contrapondo-se a esta pretensa associação do ambiente deltaico formador de turfas frente à possibilidade de formação de depósitos de carvão de valor comercial, este autor afirma que os sedimentos orgânicos depositados nos atuais deltas do Mississipi, Niger e Mahakan não constituem turfas verdadeiras tendo em vista os constituintes clásticos presentes, fato que eleva sobremaneira o seu teor em cinzas e que, neste caso, o termo turfa foi utilizado sem o devido cuidado técnico por muitos dos pesquisadores que trabalharam nestas áreas; constatações semelhantes ocorrem em outros ambientes costeiros, notadamente naqueles de mangue.

Tendo em vista que estas turfeiras dificilmente originariam carvões puros, McCabe (1984) conjectura que carvões com baixo teor de cinzas, possivelmente originados de turfas com alto teor de cinzas, foram submetidos a algum processo que pudesse atenuar tal parâmetro - de vital importância ao rank dos carvões - durante os estágios de carbonificação, possivelmente a lixiviação de inorgânicos pelos ácidos produzidos pela decomposição da matéria orgânica, o que poderia originar depósitos argilosos predominantemente cauliníticos, imediatamente sotopostos aos carvões, conhecidos como "underclays" ou "fireclays"; esta situação é atualmente encontrada no delta do Mississipi. Por outro lado, é possível, também, a existência de depósitos de arenitos quartzosos sotopostos, extremamente puros e com cimento silicoso, apresentando alto grau de depleção de feldspatos e outros constituintes, muito comuns nas regiões carboníferas da Inglaterra e conhecidos como "ganisters".

No entanto, McCabe (1984) acredita como hipótese mais provável que carvões puros devem ter sido originados de turfas puras e que a relação turfa - sistemas clásticos não é tão singela quanto o desejado por muitos modelos deposicionais. Considera como 3 as possibilidades para a formação de carvões de valor comercial e que no mínimo um destes três fatores foi importante na sua formação:

- a composição química das águas do swamp defenderam-no do influxo de clásticos;

- a turfa formou-se em turfeiras flutuantes (floating swamps) 
ou domeadas (raised swamps), as quais, por sua natureza física, são naturalmente protegidas do influxo de clastos;

• a deposição de turfa não foi contemporânea com a deposição clástica.

Aquele autor ressalta o último destes fatores como o mais importante, sugerindo que a maioria dos carvões tenha sido depositada longe da influência clástica, sendo, portanto, temporalmente distintos dos leitos clásticos sobre e sotopostos. Nos casos de evidente contemporaneidade das camadas da sequiência sedimentar, um dos outros fatores foi presumivelmente mais importante.

TURFEIRAS ASSOCIADAS AO AMBIENTE FLUVIALConstituem depósitos alongados e com baixos teores de cinzas e enxofre, consistindo de remanescentes de vegetais preponderantemente lenhosos. Podem vincular-se a sistemas anastomosados ou meandrantes, ou seja, estão sempre associados a cursos fluviais de baixo gradiente, grau variado de sinuosidade, e em planícies aluviais amplas.

A literatura reporta como características distintivas entre carvões associados a um ou outro destes sistemas fluviais a nature$\mathrm{za}$, freqüência e estruturas sedimentares das intercalações clásticas normalmente presentes (Casshyap \& Tewari 1984, Rust et al. 1984). Em última análise, tais características são frutos da evolução do perfil da bacia, bem como das taxas de suprimento sedimentar e soterramento.

Sistemas anastomados Apresentam acresção vertical predominante sobre acresção lateral, o que se reflete em elevada estabilidade lateral do canal, ou seja, pouca energia hidráulica que promova a sua migração. Os depósitos apresentam geometria multi-canal e, por isso, facies de canal e de transbordamentos são geralmente próximas. Desta forma, progradação freqüente de crevasse splays pode ocorrer, o que pode resultar em abundantes depósitos que interrompem parcial ou definitivamente a deposição orgânica nos swamps. Os depósitos de planície de inundação são completados por argilas maciças e turfas, normalmente com dimensões mais restritas que no sistema meandrante.

Sistemas meandrantes Normalmente apresentam depósitos de canal extensos lateralmente e com bases planas, formados por acresção lateral de sedimentos nas superfícies ligeiramente inclinadas das barras em pontal. Superficies erosivas internas não são comuns e os depósitos são representativos de canal único, normalmente. Os swamps formados neste tipo de sistema localizam-se mais distantes da área ativa do rio ou em extensas áreas intercanais, de forma a desenvolver depósitos orgânicos mais espessos, contínuos e puros.

Segundo Casshyap \& Tewari (1984), espessuras de até 160 metros de carvão foram observadas na India. Extensos swamps podem, ainda, vincular-se a lagos protegidos em porções mais distais, originando, também, espessos depósitos orgânicos.

\section{TURFEIRAS ASSOCIADAS AO AMBIENTE ESTUARI-}

NO Turfeiras neste ambiente seriam geradas em swamps protegidos e isolados da ação marinha por ilhas barreira, com extensão e possança ditadas pelas variações no nível do mar. Cohen (1984) propôs um modelo deposicional costeiro interbarreiras para as regiões costeiras dos estados da Geórgia, Carolina do Norte e Carolina do Sul (EUA), descrevendo em detalhes os depósitos de Snuggedy e Okefenokee, respectivamente, o mais próximo à atual linha de costa, e o membro final deste modelo, conforme esquematizado na figura 1 .

Os 3 tipos de depósitos apresentariam populações florísticas distintas, resultantes das diferentes características hidrológicas e proximidade à água do mar. $\mathrm{O}$ autor deixa claro que depósitos isentos de clásticos devem ocorrer nas zonas mais afastadas da influência marinha e que devem ser revistos os modelos que explicam depósitos de carvão puros como originados pela proteção de barreiras arenosas praiais ativas. Nesta última situação, apenas depósitos turfáceos de pequena espessura, impuros e com alto teor de enxofre seriam esperados, que poderiam vir a originar apenas delgadas lentes de folhelhos carbonosos com alto teor de cinzas e enxofre.

Pelo modelo, o depósito de Snuggedy (tipo II) seria típico de ambiente marinho marginal (estuarino alto) e aqueles desenvolvidos em marshes salinos ou lagunares (tipo I) seriam mais próximos ao mar e associados à barreiras litorâneas atuais. No caso de Okefenokee (tipo III), tanto a barreira arenosa quanto o substrato impermeável apresentam idades mais antigas que a turfa.

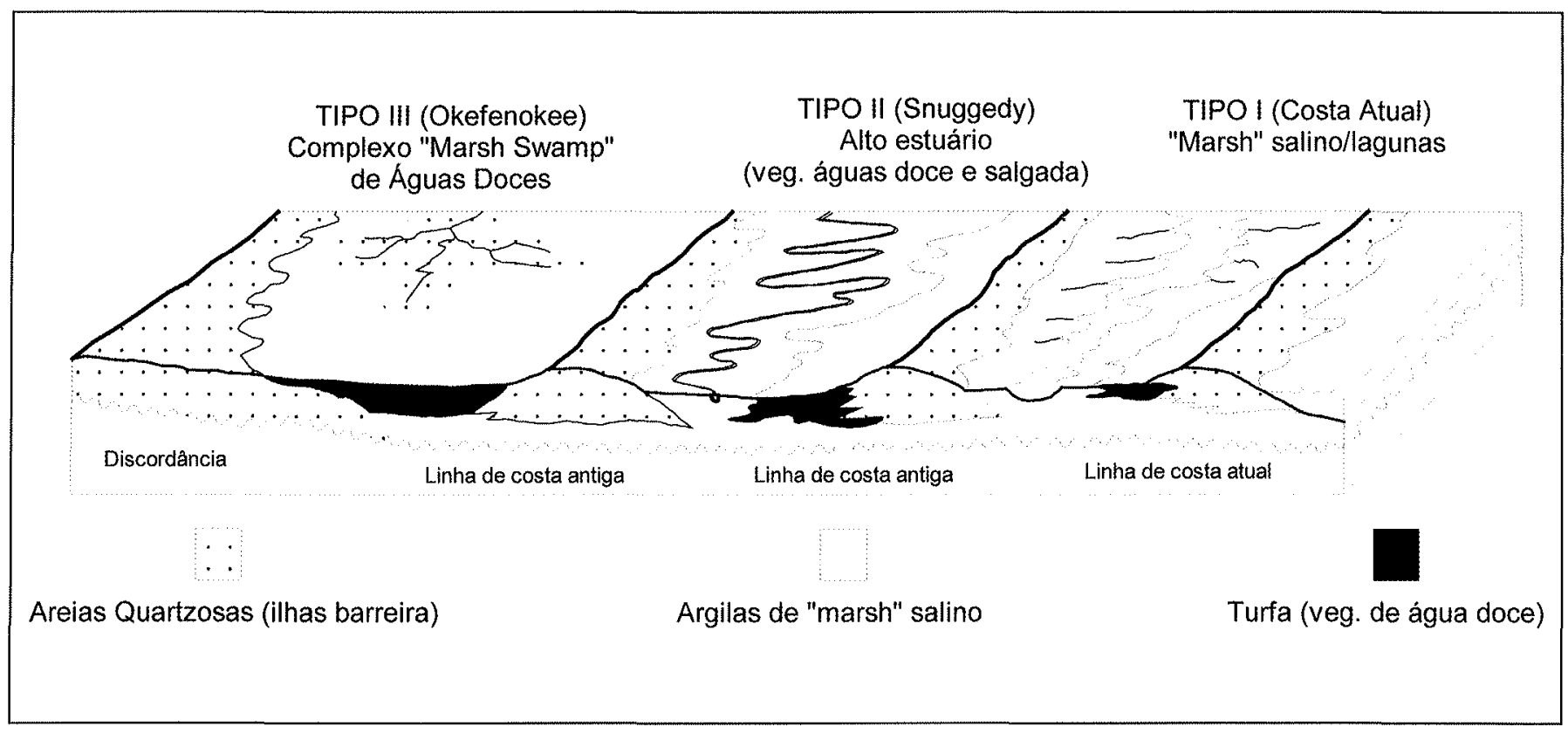

Figura 1 - Diagrama esquematizando ambientes costeiros formadores de turfa (extraido de Cohen 1984) 
DIAGNÓSTICO DAS TURFAS NO BRASIL Os resultados dos programas prospectivos empreendidos pelo sistema DNPM/CPRM durante os anos 1970 foram parcialmente apresentados num simpósio dedicado exclusivamente às turfas no XXXII CONGRESSO BRASILEIRO DE GEOLOGIA (Salvador, 1982). Entretanto, os dados ali apresentados, principalmente no que tange às reservas, são apenas estimativos tendo em vista as pesquisas não terem, ainda, sido finalizadas quando da realização do evento. Em virtude, talvez, da urgência com que os projetos foram conduzidos na ocasião, nota-se, da análise dos trabalhos apresentados, não haver, ainda, um perfeito consenso entre os técnicos envolvidos acerca dos parâmetros qualitativos do minério: a CPRM adotou uma classificação utilitária, distinguindo variedades de turfa energéticas (as de melhor qualidade) e agrícolas em função tanto do conteúdo energético (PCS $>3500 \mathrm{cal} / \mathrm{g}$ para as primeiras) quanto do teor em Cinzas, cujo limite é variável conforme o trabalho considerado, entre 25 e $40 \%$. Desta forma, as reservas estimadas de turfa energética para certas áreas limitam as cinzas em 25\%; para outras em $35 \%$; para outras, ainda, em $40 \%$; as que tivessem valores superiores a estes limites foram indiscriminadamente incluídas na categoria de "turfas agrícolas".

Áreas potenciais à ocorrência de turfa diagnosticadas nesta prospecção preliminar foram, posteriormente, detalhadas através de campanhas mais intensas de sondagens e análises laboratoriais, gerando diversos documentos apresentados ao DNPM como relatórios finais de pesquisa mineral. Consulta detalhada realizada nestes documentos serviu de base à descrição do modelo genético de nossos principais depósitos, bem como à elaboração do quadro de reservas geológicas adiante apresentados. Revelou-se, também, que, para alguns depósitos, a ausência de um limite superior quanto ao teor em cinzas para "turfa agrícola" pode gerar superestimação na avaliação de reservas deste tipo de turfa.

Houve, na mesma época, algumas outras iniciativas, principalmente no âmbito dos estados, na condução de programas prospectivos regionais (Instituto de Pesquisas Tecnológicas do Estado de São Paulo - IPT, e Metais de Minas Gerais - METAMIG).

Resultado de todo este esforço institucional, o Brasil apresenta ocorrências razoavelmente bem caracterizadas principalmente em sua extensa faixa litorânea, prospecto priorizado à época pela CPRM, além de outras em setores mais interiores do país.

A segmentação geográfica que norteou a maioria dos prom gramas prospectivos da década de 1970 induziu os técnicos da CPRM a classificarem as turfeiras brasileiras em parálicas e límnicas, de acordo com classificação geográfica estabelecida por Alpern (1976, apud Lima et al. 1982). Franchi et al. (2004), de forma mais simplificada, classificaram os depósitos brasileiros em litorâneos e interiores.

Geologia dos depósitos brasileiros Diferentemente da maioria dos depósitos existentes no Hemisfério Norte, originados a partir de lagos rasos deixados pelo recuo do gelo do último período glacial do Quaternário, as turfeiras brasileiras desenvolveram-se em depressões originadas por processos fluviais e costeiros, freqüentemente associados, que criaram canais abandonados e oxbow lakes em planícies de inundação e litorâneas, além de extensas áreas deprimidas, como lagunas ou embaiamentos isolados da influência marinha por ilhas barreira.

Constituem essencialmente turfeiras minerotróficas. Em que pese haver poucos estudos paleobotânicos nas turfeiras brasileiras, parcialmente devido à influência do clima tropical na preservação da integridade dos vegetais, os depósitos apresentam elevada diversidade florística (Villwock et al. 1980, Lemos et al. 1981, Lima et al. 1982, Lorscheitter \& Lemos 1985, Garcia 1994, Silva 1995). Aparentemente inexistem no país as raised bogs ombrotróficas, tão freqüentes no Hemisfério Norte. Embora haja depósitos de alto grau de pureza, este condicionamento genético, por si, confere às turfeiras brasileiras teores de cinzas mais elevados que os de suas congêneres originadas nas regiões frias e temperadas.

Os depósitos brasileiros são de idade holocênica (Villwock et al. 1980, Lima et al. 1982, Paione 1983a, Rocha et al. 1983, Araújo \& Veríssimo 1984, Garcia 1994, Silva 1995, Gomes, 2002).

Franchi et al. (2004) agruparam as turfeiras brasileiras em litorâneas, associadas a ambiente marinho marginal, dominantemente estuarino alto, assentadas sobre seqüências clásticas de origem lagunar, e interiores, associados predominantemente ao ambiente fluvial, desenvolvidos ao longo de extensas planícies de inundação de rios meandrantes. Fruto deste critério eminentemente geográfico, depósitos desenvolvidos em ambiente fluvial nas proximidades da desembocadura oceânica de importantes rios recebem a designação de depósitos litorâneos.

DEPÓSITOS LITORÂNEOS A Planície Costeira brasileira é marcada por extensas áreas caracterizadas por tratos morfológicos típicos de acumulação sedimentar de origem tanto fluvial (meandros abandonados, planícies de inundação, terraços aluviais), como maarinha (cordões litorâneos, lagunas, mangues, restingas), representando, todos, importantes feições ao processo de geração de turfas.

Rochas cristalinas pré-cambrianas dominam o litoral brasileiro desde o extremo sul até o Estado do Rio de Janeiro. A partir deste ponto, até a Amazônia, a faixa costeira é constituída, basicamente, por sedimentos areno-argilosos terciários (Plioceno) da Formação Barreiras, dispostos sob a forma de tabuleiros que, em diversos trechos, constituem falésias vivas (Martin et al. 1980)

Depósitos holocênicos dividem com os sedimentos Barreiras amplos trechos de exposição ao longo do litoral brasileiro, e inserem-se, tal qual os depósitos da costa atlântica da América do Norte, no contexto de variações climáticas e de nível do mar do final do Quaternário.

Associam-se a ambiente marinho marginal, dominantemente estuarino alto (podendo ser classificadas no tipo II de Cohen 1984), assentando-se, via de regra, sobre sequiências clásticas de origem lagunar. Segundo Lima et al. (1982), tiveram sua origem condicionada em grande parte pelo último grande ciclo transgressivo-regressivo, iniciado a partir da transgressão Flandriana, cujo máximo deu-se há cerca de 9.000AP.

$\mathrm{O}$ bloco diagrama da figura 2 representa a área entre os rios Pardo e Jequitinhonha, região de ocorrência das turfeiras situadas entre as localidades de Canavieiras e Belmonte, Estado da Bahia.

Segundo Martin et al. (1980), a evolução desta parte do litoral brasileiro resume-se a três grandes ciclos transgressão-regressão maiores, separados por períodos erosivos. A figura exibe o nível máximo marinho do primeiro grande ciclo transgressãoregressão da área, iniciado há cerca de $1,8 \mathrm{Ma}$, que promoveu, em sua etapa regressiva, o recuo da Formação Barreiras até sua atual área de exposição. A erosão da borda externa da Fm. Barreiras nesta fase origina os leques aluviais coalescentes em suas falésias (Qla).

O segundo ciclo transgressivo-regressivo, encerrado há cerca de 17.000AP, promove a deposição dos cordões litorâneos pleistocênicos $\left(\mathrm{Qt}_{1}\right)$, que apresentam tubos fósseis de Callianassa, artrópodes marinhos escavadores, alongados, da zona intermaré. Segundo Lima et al. (1982), o nível máximo atingido neste ciclo deu-se antes de $35.000 \mathrm{AP}$, a julgar por datações ${ }^{14} \mathrm{C}$ 


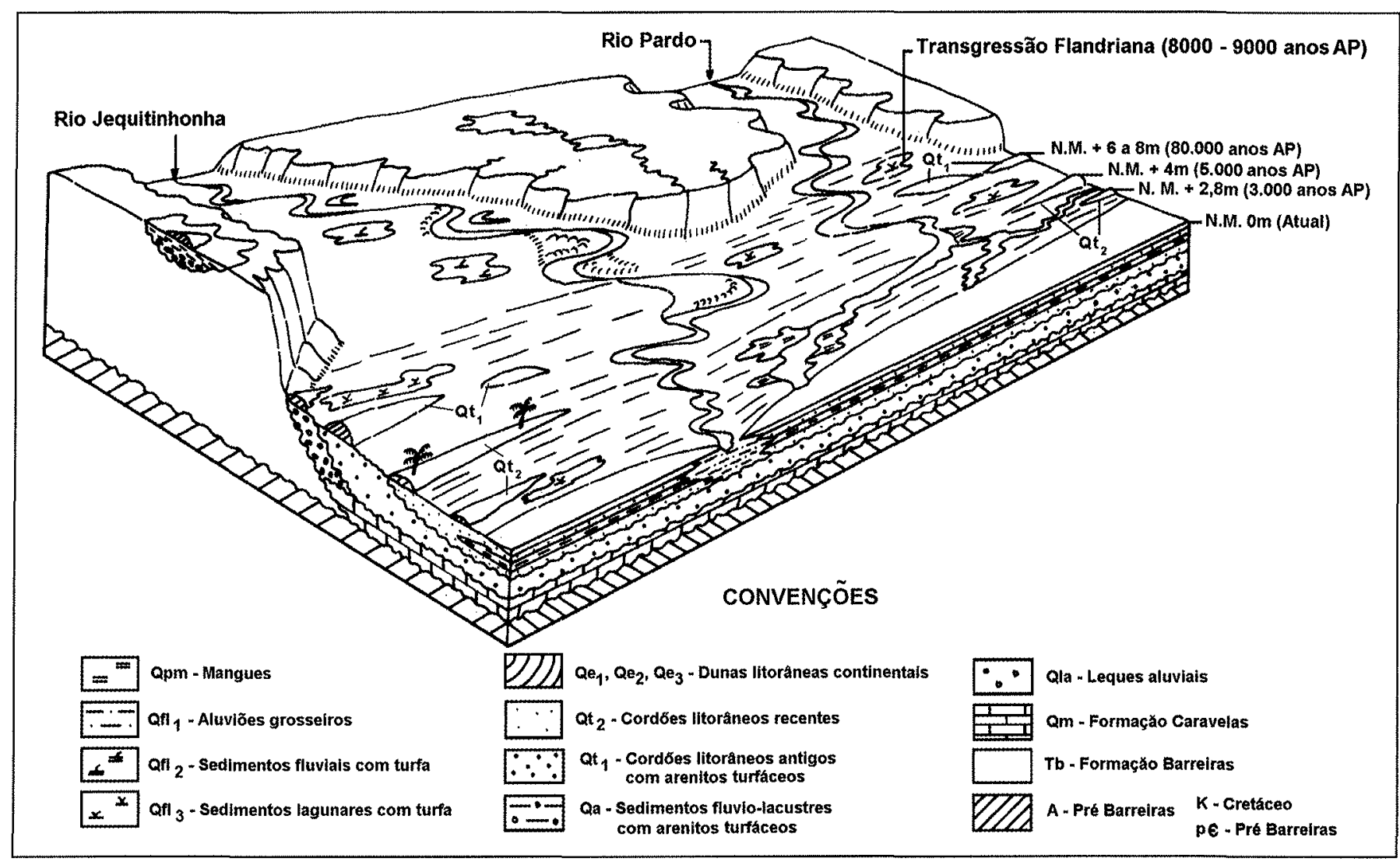

Figura 2 - Bloco diagrama esquemático da área de Canavieiras - Belmonte (BA) (mod. de Lima et al., 1982)

em pedaços de madeira, corais e conchas. A continuidade do processo regressivo trouxe o nivel do mar até $110 \mathrm{~m}$ abaixo do nível atual no final do Pleistoceno.

$\mathrm{O}$ último grande ciclo transgressão-regressão, iniciado no Holoceno, chega a ultrapassar os cordões litorâneos erigidos durante o Pleistoceno (máximo da Transgressão Flandriana) e deixa como registros 3 máximos transgressivos sucedidos por regressões. Estes máximos atingiram niveis sucessivamente decrescentes (Lima et al. 1982) e deixaram como testemunhos depósitos arenosos, também na forma de cordões paralelos à linha de costa $\left(\mathrm{Qt}_{2}\right)$. As principais turfeiras formaram-se durante as fases regressivas intercaladas (Lima et al. 1982), datadas de 51003900AP, 3600-2700AP e 2500AP até os dias atuais (Martin et al. 1980), correspondendo ao que pesquisadores do Serviço Geológico do Brasil (Lima et al. 1982, Paione 1984) denominaram de turfeiras de $1^{\mathrm{a}}, 2^{\mathrm{a}}$ e $3^{\mathrm{a}}$ gerações para os depósitos do nordeste do país. Localizam-se entre $\mathrm{Qt}_{2}$ e $\mathrm{Qt}_{1}$, ou entre as gerações de cordões $\mathrm{Qt}_{2}$.

Apresenta-se, na figura 3, a região de Barra dos Carvalhos, também Estado da Bahia, exibindo a situação geológica típica dos depósitos litorâneos: turfeiras assentadas sobre substrato de areias praiais pleistocênicas e protegidas da ação erosiva marinha pelos cordões litorâneos holocênicos.

A figura 4 esquematiza uma seção típica dos depósitos costeiros nacionais.

O perfil típico das turfeiras litorâneas inicia-se por um substrato arenoso, dos cordões litorâneos, seguindo-se sedimentos argilosos do ambiente lagunar e, finalmente, turfas, que normalmente ocorrem sem qualquer cobertura e com espessuras médias entre 1,5 e $2,0 \mathrm{~m}$.

DEPÓSITOS INTERIORES Desenvolvem-se ao longo de extensas planícies de inundação associando-se, normalmente, ao ambiente fluvial. Constituem depósitos alongados e com teores variáveis de cinzas, consistindo de remanescentes de gramíneas, preponderantemente, e de vegetais lenhosos, subsidiariamente. Vinculam-se a sistemas meandrantes, ou seja, estão sempre associados a cursos fluviais de baixo gradiente, com traçado sinuoso, e em planícies aluviais amplas. Intercalações clásticas, comuns ao ambiente, normalmente se fazem presentes na forma de argilas, representando fácies de transbordamento, ou de sedimentos mais grosseiros, resultantes do rompimento dos diques marginais (crevasse splays). Turfas de grau mais elevado de pureza são encontradas em braços abandonados ou lagos protegidos, em porções mais distais ao canal principal.

Diversos depósitos desta natureza são encontrados em alguns dos principais rios do país, com ocorrência normalmente condicionada por alguma soleira local que estabelece extensas áreas aplainadas à montante, onde o rio flui em regime meandrante. Os exemplos mais conhecidos situam-se nos rios Paraíba do Sul, Ribeira de Iguape, Jacaré-Pepira e Mogi Guaçu no Estado de São Paulo, apresentando turfas fibrosas nas partes superiores do perfil e teores de cinzas relativamente elevados, ressalvados os locais mais distantes da zona ativa do canal, como a turfeira de Eugênio de Melo, que representa parte da grande turfeira SJ-II (IPT 1979) no Vale do Paraíba.

Embora mais raras, ocorrem turfeiras associadas também ao ambiente lacustre. Níveis planálticos, não diretamente vinculados à evolução de planícies aluviais, podem apresentar pequenos depósitos turfáceos associados a bacias lacustres, ricas em sedimentos biogênicos (espongilitos), como na porção oeste do Estado de São Paulo (Franchi et al., 2004). Relativamente, ainda, a este ambiente, registra-se uma ocorrência singular em Colônia, Região Metropolitana de São Paulo, situada numa depressão circular de aproximadamente $1 \mathrm{~km}^{2}$, constituindo a fase final de preenchimento de uma cratera originada pelo provável 


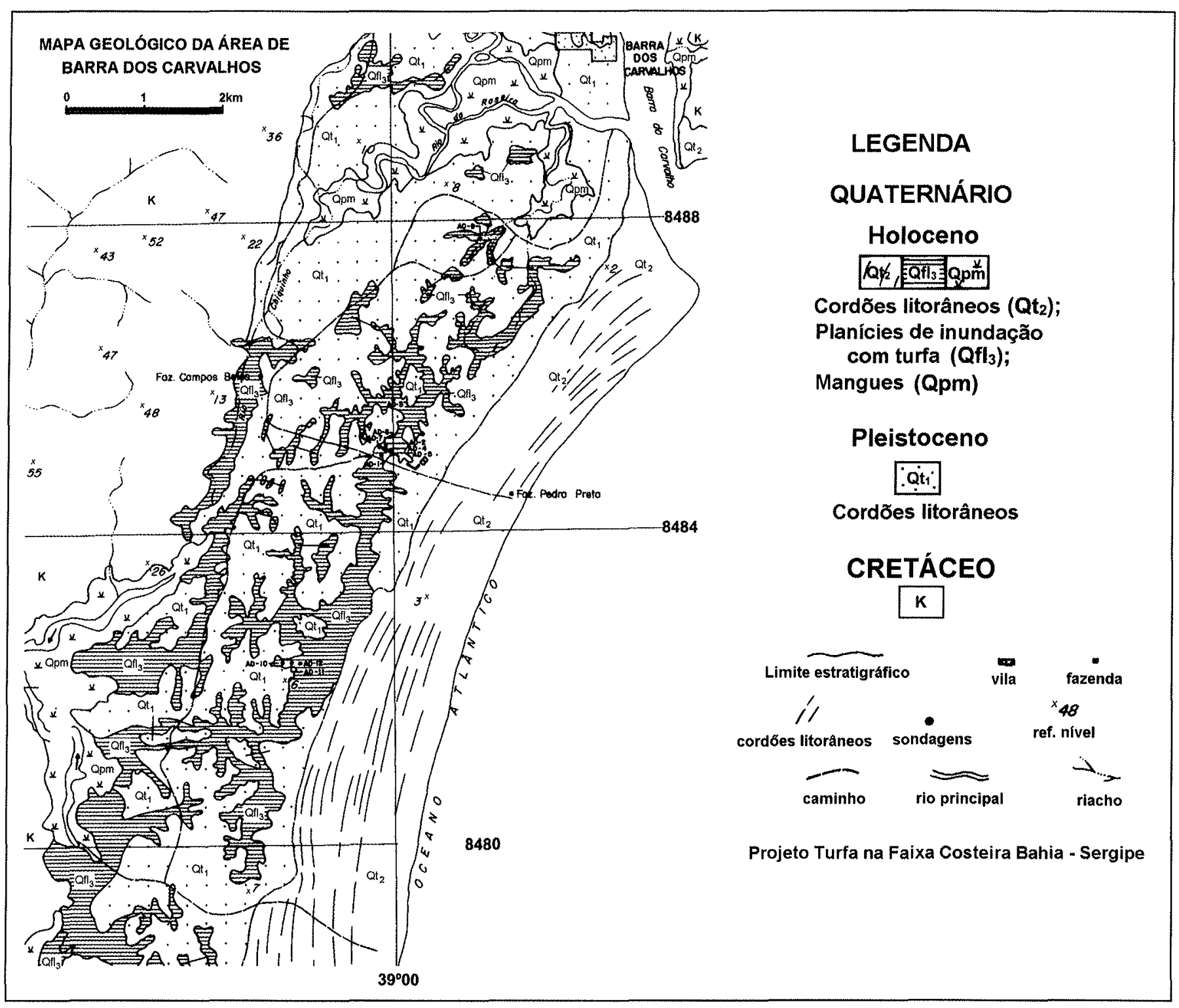

Figura 3 - Mapa geológico da região de Barra dos Carvalhos - BA (mod. de Rocha et al. 1983)

impacto de um corpo meteorítico (Riccomini et al. 1991).

A localização destes depósitos coincide, em parte, com as áreas mais desenvolvidas e densamente ocupadas do país, e, portanto, providas de maior conhecimento geológico. Apresentam-se, na figura 5, os principais setores do Estado de São Paulo que apresentam turfeiras passíveis de exploração comercial.

De acordo com Franchi et al. (2004), salvo exceções como o Estado de São Paulo, o histórico da descoberta das turfeiras interiores nem sempre se vinculou a propósito específico mas, em muitos casos, decorreu da busca de outros bens minerais, principalmente aqueles de uso imediato na construção civil (areia, argila), para atender as necessidades crescentes da ocupação humana. Estas substâncias minerais ocorrem no mesmo ambiente em que se inserem as turfeiras. É bastante plausível, assim, a descoberta de novos depósitos em regiões ainda pouco ocupadas do interior como, por exemplo, em alguns planaltos nos estados da Bahia (Correntina), Mato Grosso e Goiás (região do alto curso do Rio Araguaia).

A figura 6 exibe a localização dos principais depósitos brasileiros de turfa bem como das duas únicas unidades produtivas; é notável as principais ocorrências situarem-se ao longo de quase toda a costa do país.
RESERVAS Ao contrário do que se poderia esperar, os dados existentes no DNPM não refletem a realidade das reservas desta substância mineral tendo em vista uma distorção existente na legislação minerária. A grande maioria dos requerimentos de pesquisa mineral oficialmente protocolizados para turfa foi feita para aproveitar-se do limite máximo em área permitido em lei para esta substância (2.000ha); na realidade, objetivam outras substâncias minerais, normalmente areia ou argila destinadas a construção civil, cujo limite em área é bastante inferior. Disso decorre haver cerca de 1100 áreas requeridas em todo o território nacional, o que torna bastante dificil a investigação daquelas que efetivamente têm na turfa seu foco real.

Desta forma, mesmo reconhecendo-se o risco de incorrer-se em possiveis erros de avaliação no quadro de reservas, optou-se pela consulta a trabalhos publicados em eventos, periódicos e, principalmente, documentos e projetos executados pela CPRM - Serviço Geológico Nacional - depositados nas diversas Superintendências Regionais do órgão.

Resultado deste levantamento, apresentam-se, no quadro 1, as reservas brasileiras de turfa agrupadas por categorias, com a indicação das fontes consultadas, exclusive dados dos depósitos que apresentam turfa de qualidade inferior, ou seja, com teor de 


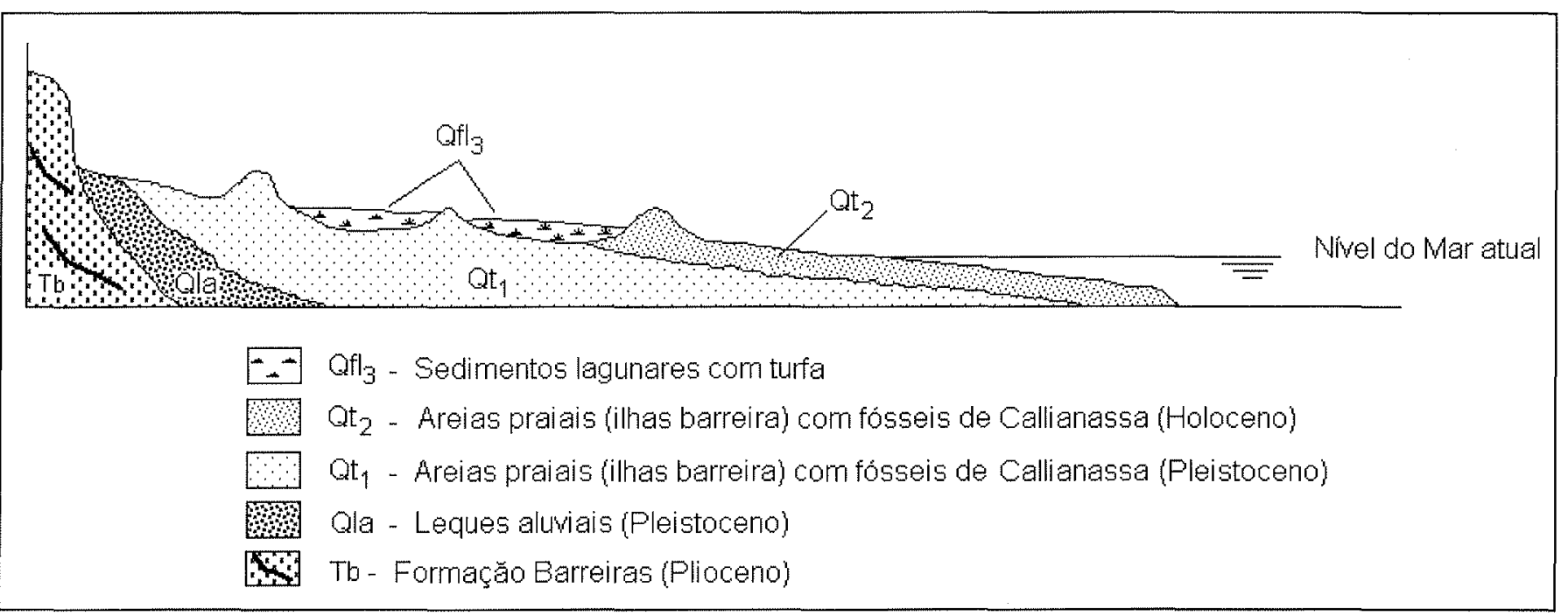

Figura 4 - Seção típica de um depósito litorâneo (baseado em Martin et al. 1980 e Lima et al, 1982)

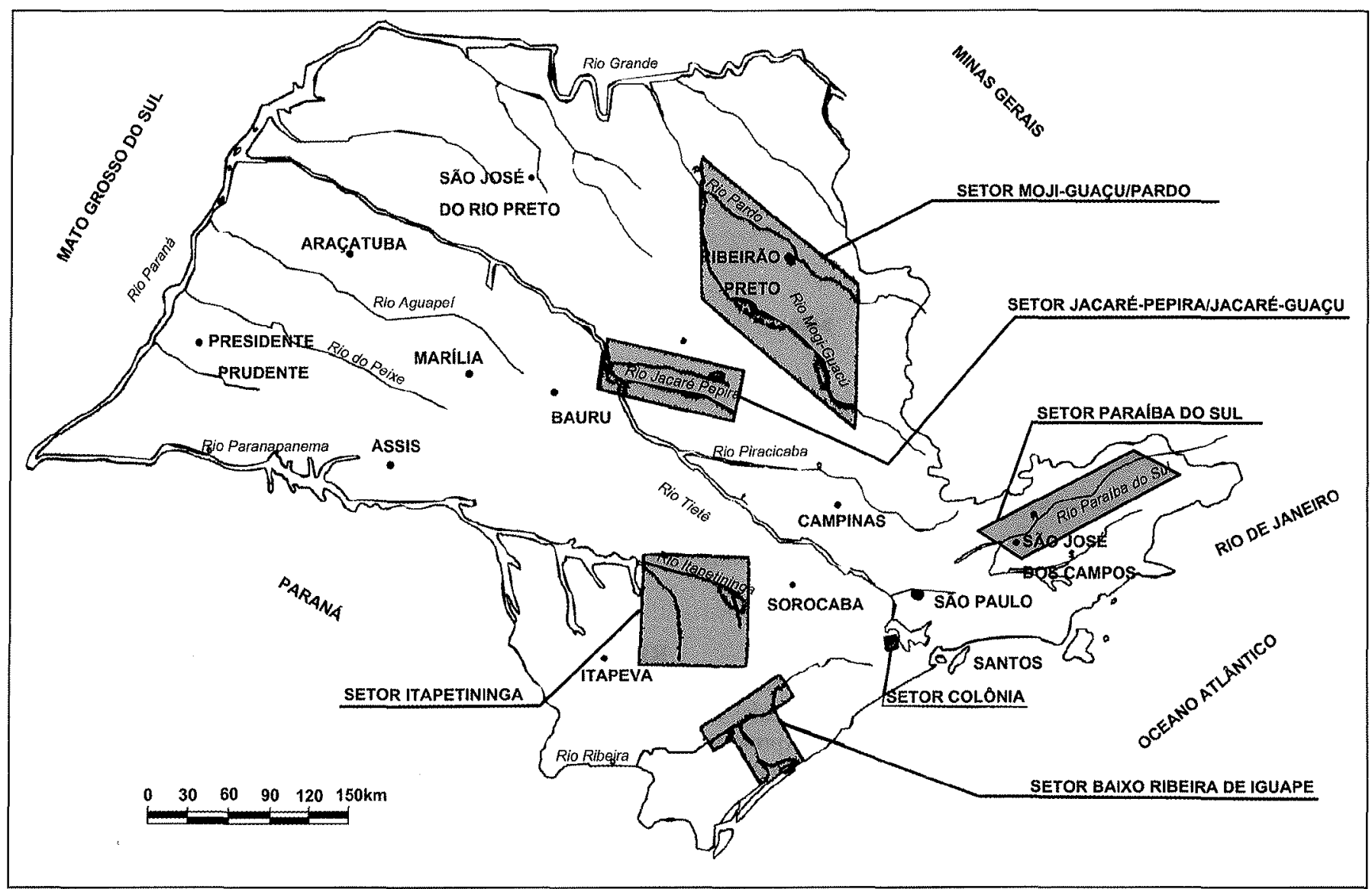

Figura 5-Principais setores fuviais portadores de turfa no Estado de São Paulo (mod. de Shimada et al. 1981)

cinzas $>40 \%$.

A análise deste quadro revela que o país dispõe de cerca de $1,1 \times 10^{9} \mathrm{~m}^{3}$ de turfas (volume in situ, ou seja, na sua umidade natural), referentes aos principais depósitos identificados naqueles programas. O baixo percentual das reservas na categoria "medida" - cerca de $20 \%$ - deve-se ao fato da pequena quantidade de trabalhos de pesquisa executados nas áreas investigadas, fruto da grande extensão em área das ocorrências, dificuldades de locomoção e acesso ao seu interior, e disponibilidade de recursos financeiros exigidos.

Nota-se do quadro que, não por acaso, cerca de $70 \%$ das reservas medidas concentram-se nos estados das regiões Sul e Sudeste, as mais desenvolvidas e populosas do país, tendo em vista as premissas iniciais realçadas no histórico da utilização da turfa no Brasil.

Considera-se que as reservas do país podem ser substancialmente aumentadas se retomados os trabalhos de prospecção nos setores mais interiores do país, e que os dados apresentados na 


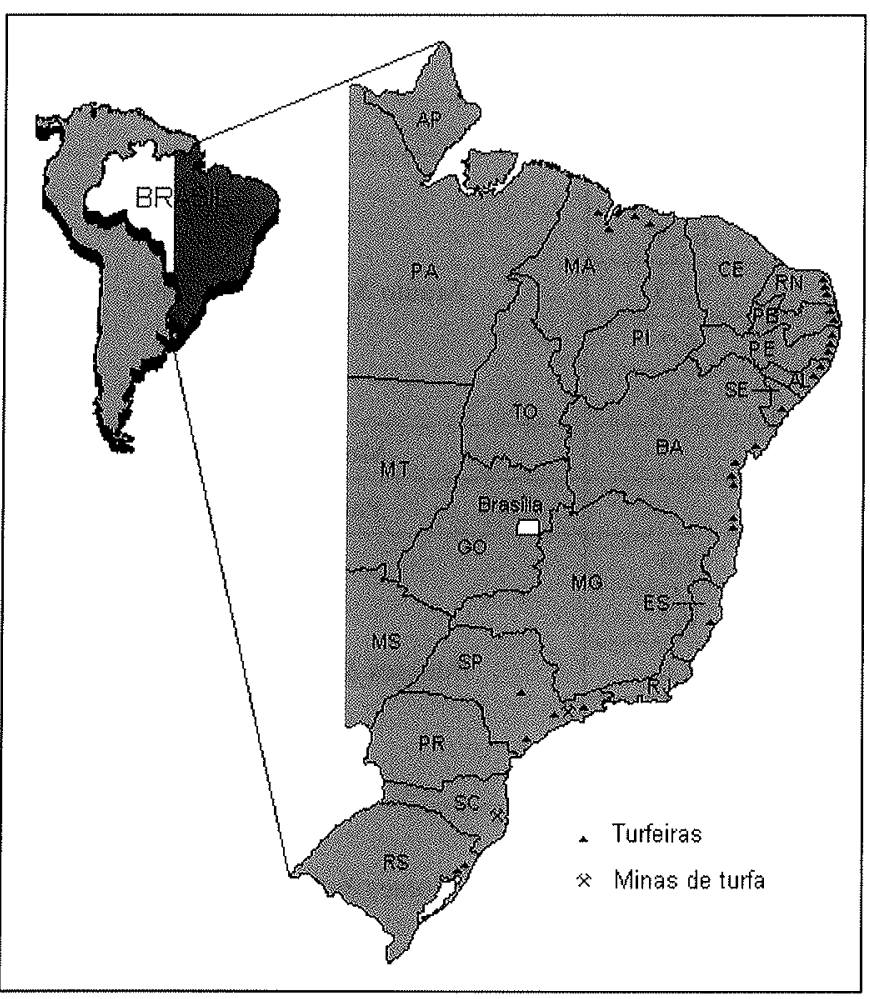

Figura 6-principais depósitos brasileiros de turfa

tabela acima podem estar um tanto distantes de refletir o real potencial brasileiro neste recurso.

PRODUÇÃO, USOS E MERCADOS A produção oficial brasileira provém principalmente das duas jazidas mencionadas no início deste trabalho, localizadas nas regiões economicamente mais desenvolvidas do país. Ambas tiveram sua exploração inicialmente voltada a aplicações energéticas da turfa.

A mina de Eugênio de Melo - - SP foi desenvolvida, através de investimentos realizados pela CESP, prevendo-se a geração de energia termoelétrica numa futura planta a ser construída nas imediações da mina, e para substituição de derivados do petróleo utilizados em caldeiras de indústrias localizadas no seu entorno. Dado estes objetivos não terem sido alcançados, a exploração foi transferida à iniciativa privada (Grupo Eucatex) que passou a comercializar, a partir do início da década de 90, exclusivamente para o mercado agrícola. A produção ao longo do ano de 2002 foi estimada em aproximadamente $85.000 \mathrm{~m}^{3}$, englobando substratos para formação de mudas, condicionadores de solo e produtos para jardinagem e paisagismo.

A mina de Balneário Arroio do Silva - SC foi aberta por um grande fabricante de pisos cerâmicos (CECRISA), que utilizou a turfa como combustível para queima em seus fornos por mais de uma década. Ao término dos anos 90 , entretanto, a turfa não mais se mostrava econômica como alternativa energética, sendo substituída por gás natural subsidiado. A partir daí, grande parte da produção foi igualmente redirecionada ao mercado agrícola. Dados do ano de 2002 apontam produção aproximada de $60.000 \mathrm{~m}^{3}$, metade destinada ao mercado agrícola, $30 \%$ para fins energéticos e $20 \%$ à revegetação de áreas degradadas pela mine- ração de carvão existente na região sul do país. A empresa Florestal S/A, que explora a mina desde 2000 , projeta crescimento de $50 \%$ na produção a ser destinada, também, para finalidades agrícolas.

Produção adicional de turfa ocorre de forma pontual em alguns estados das regiões Sul e Sudeste como subproduto da extração de outros bens minerais, sendo o material utilizado em misturas com outros insumos (principalmente esterco de aviário) para uso agrícola em geral, ou, ainda, como veículo para inoculação de microorganismos (Rhyzobium Japonicum) em cultivo de leguminosas (Fernandes \& Lazzari 1994).

Há iniciativas em andamento prevendo-se fabricar produtos destinados à remediação ambiental de áreas contaminadas por substâncias tóxicas, orgânicas e inorgânicas por parte de uma empresa que importa turfa canadense para este fim.

CONCLUSÕES A utilização da turfa no Brasil, e suas oscilações, estiveram historicamente vinculadas às alterações havidas na matriz energética do país a partir da primeira metade do século XX. Interesse institucional mais pronunciado ocorreu apenas com os choques na oferta mundial do petróleo dos anos 70 . Assim, os programas brasileiros de prospeç̧ão mineral foram conduzidos em períodos específicos, concentrando-se principalmente ao longo da ampla faixa litorânea do país.

Os conceitos presentes nas diversas classificações existentes para as turfeiras foram tentativamente reunidos de modo a agrupar estes depósitos segundo dois critérios principais: um ecológico, englobando turfeiras ombrotróficas e minerotróficas, e outro geológico, envolvendo a associação destes depósitos a ambientes deltaicos, fluviais e estuarinos.

Os depósitos brasileiros foram divididos em litorâneos, que encerram a sua grande maioria em função do direcionamento dado àqueles programas prospectivos, e interiores, associados a cursos meandrantes de importantes rios de planalto.

Salvo exceções como o Estado de São Paulo, o histórico da descoberta das turfeiras interiores nem sempre se vinculou a propósito específico mas, em muitos casos, decorreu da busca de outros bens minerais, principalmente aqueles de uso imediato na construção civil (areia, argila), para atender as necessidades crescentes da ocupação humana. Tais substâncias minerais ocorrem no mesmo ambiente em que se inserem as turfeiras. Considera-se, isto posto, que as reservas do país podem ser substancialmente aumentadas se retomados os trabalhos de prospecção, e que os dados de reservas geológicas aqui apresentados podem estar um tanto distantes de refletir o potencial do país neste recurso. O mercado brasileiro carece de litotipos dotados de homogeneidade florística, à semelhança daqueles originados nos depósitos ombrotróficos do Hemisfério Norte. A pequena produção anual do país (cerca de $145.000 \mathrm{~m}^{3}$ ) provém apenas de duas unidades produtivas que operam de acordo com a legislação mineral. Produção subsidiária ocorre como subproduto da extração de outros bens minerais que ocorrem no mesmo ambiente geológico das turfeiras.

Agradecimentos Os autores são gratos à FAPESP - Fundação de Amparo à Pesquisa no Estado de São Paulo (proc. 00/07512-7) e à CPRM - Serviço Geológico do Brasil, que gentilmente disponibilizou a documentação relativa aos projetos de pesquisa de turfa conduzidos no território nacional. 
Tabela 01 - quadro de reservas brasileiras de turfa (106 $\mathrm{m} 3$ in situ)

\begin{tabular}{|c|c|c|c|c|c|}
\hline Estado & Setor / Turfeira & Medida & Indicada & Inferida & Fonte \\
\hline \multirow{5}{*}{ MA } & Pinheiro & & & 32,9 & \multirow{5}{*}{ Araújo \& Veríssimo (1984) } \\
\hline & Ilha Grande & & & 64,7 & \\
\hline & Barreirinhas & & & 12,9 & \\
\hline & Sobradinho & & & 5,7 & \\
\hline & Carrapato-Fome & & & 21,6 & \\
\hline \multirow{7}{*}{$\mathrm{RN}$} & Ceará-Mirim & 6,3 & & & Moraes (2001) \\
\hline & Rio Maxaranguape & 0,5 & 0,48 & & Paione (1984) \\
\hline & Punaú-Piranhas & & & 8,9 & \multirow{5}{*}{ Moraes \& Caldasso (1982) } \\
\hline & Rio Pium & & & 0,7 & \\
\hline & Trairi-Ararai & & & 4,6 & \\
\hline & Goianinha-Jacu & & & 1,5 & \\
\hline & Rio Guajú & & & 4 & \\
\hline \multirow{11}{*}{$\mathrm{PE}$} & Itamaracá & & & 0,1 & \multirow{3}{*}{ Moraes \& Caldasso (1982) } \\
\hline & Jaboatão-Cabo & & & 6,3 & \\
\hline & Ipojuca & & & 3,2 & \\
\hline & Taberaba & 0,28 & & & Paione (1983b) \\
\hline & Boa Vista - Pindobal & 0,7 & 0,1 & & \multirow{3}{*}{ Paione (1983b); Moraes (2001) } \\
\hline & Cravaçu - Caranguejeira & 0,56 & 0,19 & & \\
\hline & Tavares - Tanques & 2,35 & 0,17 & & \\
\hline & Brejinho de Cima - Jaraguá & 0,24 & & & Paione (1983a) \\
\hline & Camaratuba & & & 2,4 & \multirow{3}{*}{ Moraes \& Caldasso (1982) } \\
\hline & Rio Miriri & & & 0,5 & \\
\hline & Rio Paraíba & & & 2,8 & \\
\hline \multirow{5}{*}{$\mathrm{AL}$} & Rio Meirim & 3,3 & & & \multirow{3}{*}{ Moraes (2001) } \\
\hline & Rio Pratagi & 0,7 & & & \\
\hline & Rio Manguaba & 1,9 & & & \\
\hline & Lagoa Mundaú & & & 3,3 & \multirow{2}{*}{ Moraes \& Caldasso (1982) } \\
\hline & Porto Calvo & & & 1,7 & \\
\hline SE & Santo Amaro de Brotas & 0,43 & & & Silva (1985) \\
\hline \multirow{8}{*}{$\mathrm{BA}$} & Rio das Pontes & & 6,7 & & Costa et al. (1984) \\
\hline & Barra dos Carvalhos & 5,6 & & & \multirow{2}{*}{ Rocha et al. (1983) } \\
\hline & Illha de Tinharé & 2,5 & & & \\
\hline & Faz. Monte Alegre & & & 25 & \multirow{5}{*}{ Lima et al. (1982) } \\
\hline & Faz. Lagos & & & 62,4 & \\
\hline & Vila Ouricana & & & 25 & \\
\hline & Faz. Marobar & & & 44,5 & \\
\hline & Alcobaça & & & 17,2 & \\
\hline
\end{tabular}


Tabela 01 - continuação

\begin{tabular}{|c|c|c|c|c|c|}
\hline $\mathrm{ES}$ & Córrego Grande do Meio & 40 & & & Malouf \& Tavares (1986) \\
\hline \multirow{26}{*}{$\mathrm{SP}$} & Vale do Paraíba - SJ-1 & & 18,48 & & \multirow{14}{*}{$\begin{array}{l}\text { Algarte et al. (1982); Cabral Jr. et al. (2001); } \\
\text { Aboarrage \& Oliveira (1981) }\end{array}$} \\
\hline & Vale do Paraíba - SJ-1A & & 6,23 & & \\
\hline & Vale do Paraíba - SJ-1B & & 41,09 & & \\
\hline & Vale do Paraíba - SJ-1C & & 13,7 & & \\
\hline & Vale do Paraíba - SJ-2 & & 93,76 & & \\
\hline & Vale do Paraíba - SJ-2A & & 20,92 & & \\
\hline & Vale do Paraíba - SJ-2B & & 1,81 & & \\
\hline & Vale do Paraíba - TB-1 & & 7,27 & & \\
\hline & Vale do Paraíba - TB-2 & & 19,08 & & \\
\hline & Vale do Paraíba - TB-2A & & 1,92 & & \\
\hline & Vale do Paraíba - TB-2B & & 1,05 & & \\
\hline & Vale do Paraíba - TB-3 & & 5,56 & & \\
\hline & Vale do Paraíba - TB-3A & & 2,12 & & \\
\hline & Vale do Paraíba - PD-1 & & 3,76 & & \\
\hline & Rio Moji Guaçu - MG-I & 3,26 & & & \multirow{12}{*}{ Cabral Jr. et al. (2001) } \\
\hline & Rio Moji Guaçu - MG-II & 2,32 & & & \\
\hline & Rio Moji Guaçu - MG-III & 0,3 & & & \\
\hline & Rio Moji Guaçu - MG-IV & 2,86 & & & \\
\hline & Rio Moji Guaçu - MG-V & & & 0,7 & \\
\hline & Rio Moji Guaçu - MG-VI & & & 1,9 & \\
\hline & Rio Moji Guaçu - MG-VII & 0,32 & & & \\
\hline & Rio Moji Guaçu - MG-IX & 7,04 & & & \\
\hline & Baixo Ribeira - RE I & 16,49 & & & \\
\hline & Baixo Ribeira - RE II & 4,08 & & & \\
\hline & Baixo Ribeira - SB I & & & 5 & \\
\hline & Baixo Ribeira - BR I & & & 100 & \\
\hline $\mathrm{SC}$ & Balneário Arroio do Silva & 50 & 150 & & Florestal S/A (inf. pessoal) \\
\hline \multirow{5}{*}{ RS } & Águas Claras & 18,2 & 27,8 & & \multirow{2}{*}{ Suffert (1998a, 1998b) } \\
\hline & Itapuã & 15,2 & & & \\
\hline & Barrocadas & 18 & & & \multirow{2}{*}{ Caye et al. (1983) } \\
\hline & Três Passos & 5,4 & , & & \\
\hline & TOTAL & 208,83 & 422,19 & 459,5 & \\
\hline
\end{tabular}

\section{Referências}

Aboarrage A.M. \& Oliveira C. A. 1981. Projeto Caçapava: relatório de prospecção preliminar; semidetalhe. CPRM, São Paulo.

Abreu S.F. 1973. Recursos Minerais do Brasil. 2. ed., Edgard Blucher, São Paulo, 2v.

Algarte J.P., Oliveira C.A., Aboarrage A.M. 1982. Prospecção de turfa na Bacia de Taubaté. In: SBG, Congr. Bras. Geol., 32, Anais, p. 2261-2272.

Araújo C.C. \& Veríssimo L.S. 1984. Projeto prospecção de turfa e linhito no Nordeste Setentrional. Relatório final das etapas I e II. CPRM, Fortaleza, Relatório 1681, 2v.

Cabral Jr. M., Motta J.F.M., Mello I.S.C., Tanno L.C., Sintoni A., Salvador E.D., Chieregatti L.A. 2001. Recursos minerais do Fanerozóico do Estado de São Paulo. Geociências, 20:105-159.

Casshyap S.M. \& Tewari R.C. 1984. Fluvial models of the Lower Permian coal measures of Son-Damodar Valley basins, India. In: R.A Rahmani \& R.M. Flores (eds.) Sedimentology of coal and coalbearing sequences. Spec. Publ. Int. Assoc. Sediment., Blackwell Scient. Public., Oxford. v.7, p.121-147

Caye B.R., Amaral J.A.F., Machado J.L.F., Santos R.G., Wildner W. 1983. Projeto Torres-Gravatai. Bloco Banhado dos Touros. CPRM, Porto Alegre, Relatório $1335,4 \mathrm{v}$.

Clymo R.S. 1983. Peat. In: A.J.P. Gore (ed.) Mires: swamp, bog, fen and moor. Elsevier, Amsterdan, pp.: 159-224 (Ecosystems of the world, 4A). 
Cohen A.D. 1984. The Okefenokee Swamp: a low sulphur end-member of a shoreline-related depositional model for coastal plain coals. In: R.A. Rahmani \& R.M. Flores (eds.) Sedimentology of coal and coal-bearing sequences. Spec. Publ. Int. Assoc. Sediment., Blackwell Scient. Public., Oxford, v.7 p.231-240.

Costa I.V.G., Gonçalves J.C.V., Guimarães J.T., Lima R.C.C. 1984. Projeto Salvador - Área de Conde. CPRM, Salvador, Relatório 1497, $52 \mathrm{p} .+$ anexo.

Fernandes J.L. \& Lazzari R.T. 1994. Utilização de turfa como veículo para inoculante agrícola contendo "R. Japonicum". In: SBG, Congr. Bras. Geol., 38, Bol. Res. Expandidos, p. 438-442.

Franchi JG., Sígolo J.B., Lima J.R.B. 2003. Turfa utilizada na recuperação ambiental de áreas mineradas - metodologia para avaliação laboratorial, Rev. Bras. Geoc., 33 (no prelo).

Franchi J.G., Motta J.F.M., Uosukainen H., Sígolo J.B. 2004. Peat in Brazil: geology, reserves, production and use. In: IPS, International Peat Congress, 12, Proceedings, p. 627-632.

Garcia M. J. 1994. Palinologia de turfeiras quaternárias do médio vale do Rio Paraíba do Sul, Estado de São Paulo. Tese de Doutoramento, Instituto de Geociências, Universidade de São Paulo, S. Paulo, $3 v$.

Gomes A.J.P. 2002. Carvão do Brasil/Turfa Agricola - geologia, meio ambiente e participação estratégica na produção de eletricidade no sul do Brasil, EST, Porto Alegre, 164p.

IPT Instituto de Pesquisas Tecnológicas do Estado de São Paulo. 1979. Estudo das possibilidades de aproveitamento de turfa no Estado de São Paulo. IPT, São Paulo, Relatório 12.761, 191p.

Lemos V.B., Siedlecki K.N., Oliveira J.M.P., Lamb L., Baptista M.L. 1981. Considerações preliminares quanto à prospecção de áreas turfosas. In: SBG, Simp. Reg. Geol., 3, Atas, p. 243-258.

Lenz G.R. 1984. Turfa - Métodos de lavra e opções para uso no Nordeste brasileiro. Rev. Bras. Geoc., 14:111-119.

Lima R.C.C., Rocha A.J.D., Costa I.V.G., Silva J.F. 1982. Projeto turfa na faixa costeira Bahia-Sergipe. CPRM, Salvador, (Relatório 1146), $2 \mathrm{v}$

Lorscheitter M.L. \& Lemos V.B. 1985. Estudo palinológico preliminar em turfeiras do Estado do Paraná. In: SBG, Simp. Sul-Bras. Geol., 2, Atas, p. 461-473

Malouf R.F., Tavares W.P. 1986. Projeto Turfa no Espirito Santo - Turfeira Córrego Grande do Meio. Relatório final sobre a preparação da lavra experimental. CPRM, Belo Horizonte, Relatório 1869, $20 \mathrm{p}$. + anexos.

Martin L., Bittencourt A.C.S.P., Vilas Boas G.S., Flexor J.M. 1980. Mapa Geológico do Quaternário costeiro do Estado da Bahia - 1:250.000 - Texto explicativo. Secretaria das Minas e Energia/Coordenação da Produção Mineral, Salvador, $60 \mathrm{pp}$.

Moore P.D. 1989. The ecology of peat-forming processes: a review. International Journal of Coal Geology, 12:89-103.

Moraes J.F.S. 2001. Turfa nos estados de Alagoas, Paraiba e Rio Grande do Norte. CPRM, Recife, Informe de Recursos Minerais, Série Oportunidades Minerais - Exame Atualizado de Projeto, $\mathrm{n}^{\circ} 14$, $16 \mathrm{p}$.

Moraes J.F.S. \& Caldasso A.L.S. 1982. Síntese dos conhecimentos atuais sobre turfa na região nordeste oriental. In: SBG, Congr. Bras. Geol., 32, Anais, p. 2252-2260.

Oliveira C.A. 2001. Turfa de São José dos Campos, Estado de São Paulo. CPRM, São Paulo, Informe de Recursos Minerais, Série Oportunidades Minerais, Exame Atualizado de Projeto, ${ }^{\circ} 24,14 p$.
Paione J.A. 1983a. Projeto Rio Tinto - Setor Rio Tinto II. CPRM, Recife, Relatório 1378, 73p. + anexos

Paione J.A. 1983b. Projeto Rio Tinto - Setor Rio Tinto. CPRM, Recife, Relatório $1310,51 \mathrm{p} .+$ anexos

Paione J.A. 1984. Projeto Rio Tinto-Setor Rio Maxaranguape. Recife, CPRM, Relatório 1453, 62p. + anexos

Petroni S.L.G. 2004. Avaliação cinética e de equilíbrio do processo de adsorção dos ions dos metais cádmio, cobre e níquel em turfa. Tese de Doutoramento, Instituto de Pesquisas Energéticas e Nucleares, Universidade de São Paulo, S. Paulo, $121 \mathrm{p}$.

Petroni S.L.G., Pires M.A.F., Munita C.S. 2000. Adsorção de zinco e cádmio em colunas de turfa. Química Nova, 23:477-481.

Riccomini C., Turcq B., Martin L., Moreira M. Z., Lorscheitter M. L. 1991. The Colônia Astrobleme, Brasil. Journal of the Geological Institute, 12:87-94.

Rocha A.J.D., Guimarães J.T., Azevedo R.R. 1983. Projeto COPENER/ SME. Turfeira de Barra dos Carvalhos - llha de Tinharé. CPRM, Salvador, Relatório 1391, 3v.

Rust B.R., Gibling M.R., Legun A.S. 1984. Coal deposition in an anastomosing-fluvial system: the Pennsylvanian Cumberland Group south of Joggins, Nova Scotia, Canada. In: R.A. Rahmani \& R.M. Flores (eds.) Sedimentology of coal and coal-bearing sequences. Spec. Blackwell Scient. Public., Oxford, Publ. Int. Assoc. Sediment., v.7, p. 105-120.

Ryer T.A. \& Langer A.W. 1980. Thickness change involved in the peatto-coal transformation for a bituminous coal of Cretaceous age incentral Utah. J. Sediment. Petrol., 50:987-992.

Santos, M. D. C. 1998. Estudo dos mecanismos de adsorção em meio ácido dos metais chumbo e zinco em uma turfa de Jaconé-RJ. Tese de Doutoramento, Escola Politécnica, Departamento de Engenharia de Minas, Universidade de São Paulo, S. Paulo, 130p.

Shimada H., Motta J.F.M., Cabral Jr. M., Nakano S. 1981. Prospecção de turfa no Estado de São Paulo. In: SBG, Simp. Reg. Geol., 3, Atas, p. 259-273.

Shotyk W. 1988. Review of the inorganic geochemistry of peats and peatland waters. Earth-Science Reviews, 25:95-176.

Silva C.M. 1995. Palinologia das turfeiras de São José dos Campos. Dissertação de Mestrado, Instituto de Geociências, Universidade Federal do Rio de Janeiro, R. Janeiro, 143p

Silva J.F. 1985. Turfeira Santo Amaro de Brotas. Relatório Final de Pesquisa - processos DNPM 870.055/84 e 870.155/84. CPRM, Salvador, $1 \mathrm{v}$.

Suffert T. 1998a. Turfa da região de Itapuã, Estado do Rio Grande do Sul. CPRM, Porto Alegre, Informe de Recursos Minerais, Série Oportunidades Minerais, Exame Atualizado de Projeto, $\mathrm{n}^{\circ} 12,14 \mathrm{p}$.

Suffert T. 1998b. Turfa de Aguas Claras, Estado do Rio Grande do Sul. CPRM, Porto Alegre, Informe de Recursos Minerais, Série Oportunidades Minerais, Exame Atualizado de Projeto, $\mathrm{n}^{\circ}$ 13, 14p.

Villwock J.A., Dehnhardt E.A., Loss E.L., Hofmeister T. 1980. Turfas da província costeira do Rio Grande do Sul: geologia do depósito de Águas Claras. In: SBG, Congr. Bras. Geol., 31, Anais, p. 500-512.

Zimmermann D.G. 2001. Solos construidos em áreas mineradas como fundamento para recuperar o ambiente. Dissertação de Mestrado, Centro de Ciências Agrárias, Universidade Federal de Santa Catarina, $88 \mathrm{p}$.

Manuscrito A-1542 Revisão aceita em 18 de agosto de 2006 